\title{
Herencias de Derrida
}

\author{
CRISTINA DE PERETTI \\ UNED, Madrid
}

\begin{abstract}
RESUMEN. Aquí se presenta una visión panorámica de la herencia filosófica legada por Derrida, pasando revista a los rasgos más característicos del pensamiento derridiano, que se definió a sí mismo como «cierta experiencia aporética de lo imposible». Tras examinar conceptos como los de «fidelidad», «espectro», «acontecimiento»y, por supuesto, «deconstrucción», se hace ver que - según Derrida - la tarea filosófica consistiría en analizar los estratos y sedimentos que configuran el discurso dentro del cual pensamos, con el fin de abrir nuevas perspectivas de futuro $y$ descubrir otros posibles sentidos distintos a los refrendados por la tradición.
\end{abstract}

\begin{abstract}
We present here a panoramic vision of the philosophical legacy bequeathed by Derrida, examining the most characteristic traits of Derridian thought, which defined itself as «a certain aporetic experience of the impossible». After examining concepts like those of «fidelity», «specter», «event» and, of course, «deconstruction», we show that, according to Derrida, the philosophical task would consist in analyzing the strata and sediments that configure the discourse within which we think, with the aim of opening new future perspectives and of discovering other possible meanings different from those endorsed by tradition.
\end{abstract}

[...] la muerte del otro, no sólo pero sobre todo si se lo quiere, no anuncia una ausencia, una desaparición, el fin de tal o cual vida, a saber, de la posibilidad de que un mundo (siempre único) aparezca a tal ser vivo. La muerte declara cada vez el fin del mundo en su totalidad, el fin de todo mundo posible y, cada vez, el fin del mundo como totalidad única, por lo tanto, irreemplazable y, por consiguiente, infinita» (J. Derrida).

A lo largo de su prolífica obra, Derrida nunca ha dejado de pensar en torno a la muerte: la suya y la de los demás, los otros, amigos o desconocidos pero también seres vivos en general. Y esta reflexión sobre la muerte, Derrida la ha realizado en contextos muy distintos, desde perspectivas muy variadas, con estilos muy diferentes: en conversación con otros pensadores; a raíz de sus reflexiones en torno al psicoanálisis, la amistad o los espectros; a modo "de «adiós» con ocasión de la muerte de amigos y compañeros, etc., mostrando que cada vez, en cada circunstancia, la muerte de cada cual implica el fin 
del mundo, un fin del mundo único, singular, insustituible ${ }^{1}$. Por desgracia, hoy nos toca a nosotros hacernos cargo de su muerte, de la de Derrida, fallecido no hace todavía ni dos meses en el momento en que, a finales de noviembre de 2004, comienzo a escribir este artículo en el que se me pide que, más allá de ese duelo imposible por aquel que para mí nunca dejará de ser mi maestro a la vez que mi amigo, exponga cuál es la herencia filosófica que Derrida nos ha dejado.

Ahora bien, la reflexión sobre la herencia, sobre qué significa precisamente heredar tampoco es en absoluto ajena al pensamiento de Derrida, a su legado. Es evidente que todos nosotros, todo ser humano, somos herederos de arriba abajo: heredamos una tradición, una cultura, una lengua. Sin embargo, heredar, para Derrida, no consiste simplemente en recibir algo que nos viene dado y que, a partir de entonces, podemos decir ya que poseemos sin más. Sólo hay herencia cuando el legado mantiene en reserva algo indecidible, algo secreto, cuando es lo suficientemente múltiple y contradictorio como para que, al heredar, tomemos necesariamente cierta iniciativa y asumamos el riesgo de interpretar esa herencia, de seleccionarla y de alterarla. Dicho de otra manera, heredar no sólo responde a una exhortación, sino que, para que la respuesta a dicha conminación sea una afirmación activa y responsable, sólo cabe ratificarla con nuestra firma a la vez que, con ésta, transformamos, reactivamos e inventamos aquello mismo que heredamos. Sólo así, siéndole infiel por fidelidad, cabe hacerse cargo de una herencia.

No hay fidelidad posible para alguien que no pudiese ser infiel. A partir de la infidelidad posible es como se logra la herencia, como se la asume, como se retoma y se refrenda la herencia para hacer que vaya a parar a otro sitio, que respire de otra forma. Si la herencia consiste simplemente en mantener cosas muertas, archivos y en reproducir lo que fue, no es lo que se puede llamar una herencia. No se puede desear un heredero o una heredera que no invente la herencia, que no se la lleva a otra parte por fidelidad. Una fidelidad infiel. Volvemos a encontrarnos con esa doble inyunción que siempre me acompaña ${ }^{2}$.

«No hay fidelidad posible para alguien que no pudiese ser infiel». «En la medida en que la herencia y la fidelidad pertenecen al ámbito de la promesa, la cual no promete tanto algo concreto cuanto com-promete, dice Derrida, a establecer un vínculo incondicional con el otro y en que, para ser tal, para no

${ }^{1}$ Cfr., por ejemplo, Chaque fois unique, la fin du monde, Paris, Galilée, 2003.

2 Sur parole, París, Éditions de l'Aube, 1999, p. 60. Cfr. también, por ejemplo, Échographies - de la télévision (con B. Stiegler), París, Galilée-INA, 1996, pp. 33 ss., 79 ss., 99 ss., 124 ss., 135 y 147 ss.

Por mi parte, para traducir el término francés injonction utilizo la palabra castellana «inyunción», recuperando así el uso del antiguo verbo «inyungir», «imponer una cosa a alguien». Cfr. la nota de traducción de Espectros de Marx. J. M. Alarcón y C. de Peretti (trads.), Madrid, Trotta, 1995, p. 12. 
convertirse en una mera previsión anticipable, la promesa alberga siempre necesariamente cierta reserva de incertidumbre ("la promesa promete con ese modo fundamental del 'quizás', e incluso del 'peligroso quizás' que inaugurará, como profetiza Más allá del bien y del mal, la palabra de los filósofos del porvenir "'), la amenaza del incumplimiento, de la infidelidad, de la traición o de la pervertibilidad siempre forma necesariamente parte de la estructura de aquéllas».

Con todo esto, me estoy refiriendo ya a otros dos de los grandes legados del pensamiento derridiano que se define a sí mismo como «cierta experiencia aporética de lo imposible», una experiencia que, como tal, va a entrañar un pensamiento diferente tanto en el terreno ético-político como en el del acontecimiento, del «tener-lugar».

La experiencia de la aporía o, como también la denomina Derrida, la experiencia de la indecidibilidad o del double-bind (de la «doble inyunción que siempre me acompaña», como él mismo apunta en uno de los textos ya citados), no es ni un «quedar en suspenso de la indiferencia» ni la «neutralización interminable de la decisión»; tampoco «viene a manifestar el límite, la impertinencia, la incompetencia de un dispositivo de decisión» ${ }^{4}$, sino que, por el contrario, resulta imprescindible para tomar una decisión y para asumir una responsabilidad «dignas de ese nombre». Si, de antemano, sabemos o creemos saber cómo hemos de actuar, si, por adelantado, conocemos las respuestas necesarias para resolver un problema, lo que estamos haciendo es desarrollar casi mecánicamente un programa, algo que anteriormente ya estaba establecido, previsto, calculado y decidido. No tomamos ninguna decisión, no asumimos ninguna responsabilidad. Simplemente dejamos que las cosas sigan su curso.

Una decisión responsable debe obedecer a un «hay que» que no debe nada, a un deber que no debe nada, que debe no deber nada para ser un deber, que no salda ninguna deuda, un deber sin deuda y, por consiguiente, sin deber ${ }^{5}$.

Este «deber sin deuda y, por consiguiente, sin deber» implica que, a la hora de tomar una decisión, no nos dejemos guiar por las obligaciones, las reglas y los criterios previamente establecidos; lo cual no significa, sin más, que tengamos que transgredir las leyes, que contravenir las normas, que oponernos a cualquier deber. Toda contrarregla también es una regla $y$, por consiguiente, no sólo supone una seguridad, una garantía, sino que asimismo forma parte de un programa. Sin embargo, de lo que aquí se trata, precisamente, es que la decisión y la responsabilidad no respondan a ningún saber ni a ningún cálculo. De lo que se trata es de inventar cada vez una

\footnotetext{
${ }^{3}$ Politiques de l'amitié, París, Galilée, 1994, p. 46.

${ }^{4}$ Altérités (con P. J. Labarrière), París, Osiris, 1986, pp. $32-33$.

${ }_{5}^{5}$ Apories. Mourir - s'attendre aux «limites de la vérité», París, Galilée, 1996, p. 37.
} 
decisión única a partir del análisis siempre interminable de cada situación particular. Sólo así, afirma Derrida, podrá una decisión ser digna de ese nombre, sólo así podrá la responsabilidad ser infinita. Sólo así podrán ambas ser incondicionales... e imposibles.

Ahora bien, entre lo posible y lo imposible, explica Derrida, no existe ninguna contradicción lógica. «Lo imposible», tal y como él lo entiende, no es lo contrario de lo posible, no es la simple modalidad negativa de éste, sino, por el contrario, la condición misma de posibilidad de lo posible, siempre y cuando no entendamos dicha condición de posibilidad como el mero despliegue o la simple actualización de lo que ya es posible ${ }^{6}$.

Son muchas las problemáticas o - como él suele más bien denominarlos - los «motivos» que, a lo largo de sus textos, Derrida califica de «imposibles» (me estoy refiriendo, por ejemplo, al don, a la hospitalidad, al testimonio, al perdón pero asimismo al acontecimiento, a la invención, a la herencia, a la decisión y a un largo etcétera ${ }^{7}$ ) ya que éstos únicamente son posibles como tales, como incondicionales, allí donde son o parecen imposibles, allí donde su posibilidad como incondicionales consiste en su imposibilidad. Dicho de otra forma: sólo porque resultan imposibles, son incondicionales.

Lo incondicional: aquello que, al estar ligado a un deber sin deber, a un deber que no debe nada, rompe el círculo de la economía (esto es, del intercambio, de la deuda, de la reciprocidad, de la compensación o del simple reconocimiento) y que, al no ser posible más que como imposible, rompe igualmente el círculo de la ontología. ¿Quiere esto decir que la imposibilidad - $\mathrm{o}$ independencia - ontológica de estos motivos incondicionales derridianos los convierte entonces en simples utopías?

«No la utopía, lo im-posible», afirmará Derrida ${ }^{8}$.

La deconstrucción más rigurosa no se ha presentado nunca [...] como algo posible. Yo diría que no pierde nada por confesarse imposible, y quienes se regocijasen por eso demasiado rápido, no pierden nada por esperar. El peligro para una tarea de deconstrucción sería antes bien la posibilidad, y convertirse en un conjunto disponible de procedimientos regulados, de prácticas metódicas, de caminos accesibles. El interés de la deconstrucción, de su fuerza y de su deseo, si los tiene, es cierta expe-

\footnotetext{
${ }^{6}$ Cfr., por ejemplo, Papier Machine, París, Galilée, 2001, p. 303.

${ }^{7}$ Los textos que se podrían citar al respecto son demasiado numerosos. Me limitaré, pues, a mencionar sólo algunas referencias en relación con varios de los «motivos» mencionados (en algu-nas de las cuales, por lo demás, Derrida explica perfectamente cómo entiende lo imposible como condición de posibilidad de lo posible): «Une certaine possibilité impossible de dire l'événement», en J. Derrida, G. Soussana \& A. Nouss (eds.), Dire l'événement, est-ce possible? Séminaire de Montréal, pour Jacques Derrida, París, L'Harmattan, 2001, pp. $79 \mathrm{ss} \mathrm{(y,} \mathrm{más} \mathrm{concretamente,} \mathrm{por}$ ejemplo, pp. 92-93, en relación con el don); Papier Machine, ed. cit., p. 294 (en relación con el perdón incondicional); Échographies - de la télévision, ed. cit., pp. 103 ss. (en relación con el testimonio); De l'hospitalité, París, Calmann-Lévy, 1997, passim; «Psyché. Invention de l'autre», en Psyché. Inventions de l'autre, París, Galilée, 1987, pp. 11 ss. (en relación con la invención).

8 Papier Machine, ed. cit., pp. 349 ss.
} 
riencia de lo imposible [...] la experiencia de lo otro como invención de lo imposible, en otros términos, como la única invención posible 9 .

De lo que se trata es de hacer lo imposible, de responder a lo imposible. Estos motivos incondicionales, absolutos, hiperbólicos son heterogéneos e irreductibles a sus «contrarios» condicionales, calculables y programables. Sin embargo, a la vez son indisociables e inseparables de ellos, ya que de ninguna manera se pueden pasar por alto las numerosas urgencias prácticas insoslayables e indiferibles que constantemente han de resolverse aquí y ahora. De manera que será preciso que, en cada ocasión particular, se negocie de forma singular (esto es, se invente cada vez la negociación ${ }^{10}$ ) con lo posible siempre en nombre de lo imposible, de lo incondicional, de lo innegociable: de lo que Derrida denomina la «justicia» ${ }^{11}$ (irreductible al derecho pero, a la vez, indisociable de él) o el respeto incondicional al otro, a su alteridad singular e irreductible; la apertura ilimitada a lo que está por venir, a aquel(lo) que no conocemos ni anticipamos en modo alguno y cuyos efectos nos resultan asimismo imprevisibles: el acontecimiento, lo radicalmente otro, lo arribante absoluto, el otro espectral.

Me gustaría detenerme un momento en la figura del espectro, del otro espectral que Derrida desarrolla más pormenorizadamente en Spectres de Marx. En primer lugar, la lógica de la espectralidad, muy similar en algunos aspectos a la lógica derridiana de la restancia ${ }^{12}$, supone un importante desafío tanto para una ontología o para un pensamiento del origen como para una

9 Psyché, ed. cit., pp. 26-27.

to «[...] es preciso negociar lo no-negociable. Esta necesidad no es un mal menor empírico: a través de su indecidibilidad misma es un imperativo. Abre el espacio de la decisón y, por lo tanto, de la responsabilidad (moral, jurídica o política). Y lo abre antes incluso de la negociación entre lo imperativo y lo hipotético, lo incondicional y lo condicional, lo no-negociable y lo negociable» «Du "sans prix", ou le "juste prix" de la transaction», en R. P. Droit, Comment penser l'argent?, París, Le Monde Éditions, 1992, p. 398.

«Cuando se dice negociación, se dice convenio, transacción. Es precisa la transacción, pero está por inventar... Una buena transacción es una invención tan original como la invención más inédita. Es precisa la transacción en nombre de lo intratable, en nombre de lo incondicional, en nombre de algo que no tolera la transacción, y ésta es la dificultad. La dificultad del pensamiento como dificultad "política"», Échographies - de la télévision, ed. cit., p. 93.

${ }_{11}$ Con respecto a la justicia, cfr., por ejemplo, Spectres de Marx, París, Galilée, 1993, pp. 47 ss. Derrida califica en ocasiones la justicia como «lo indeconstructible», op. cit., p. 56; «La déconstruction de l'actualité», en Passages, París, núm. 57, septiembre de 1993, p. 70; Force de loi, París, Galilée, 1994 , p. 35 . Con respecto a lo indeconstructible - aquello que no se deja deconstruir pero no porque la exceda, no en virtud de unos fundamentos sólidos a salvo de la deconstrucción, sino como el espaciamiento mismo de ésta, como aquello que le proporciona impulso y justificación-, cfr. además de las referencias anteriores, Sauf le nom, París, Galilée, 1993, p. 104, así como el artículo de P. Vidarte y mío titulado «L'auto-délimitation déconstructive: la démocratie indéconstructible?», en M. L. Mallet (dir.), La démocratie à venir. Autour de Jacques Derrida, París, Galilée, 2004, pp. 129 ss.

12 Dicha lógica -0 , si se prefiere, a-lógica, puesto que pone en entredicho al logos- tiene su antecedente en el movimiento de la huella como simulacro de presencia dislocada, como estructura de reenvío constante, cfr., por ejemplo, De la grammatologie, París, Minuit, 1967, p. 90. 
lógica de la identidad o de las oposiciones binarias jerarquizadas. El espectro, al igual que la ceniza, el resto o la ruina ${ }^{13}$, reste - dice Derrida en francés-: queda, permanece, pero también puede desaparecer. Ahora bien, si queda, no será al modo de una esencia, de una sustancia, de una entidad ontológica que sí permanece indivisible, inalterable e inmutable, esto es, idéntica consigo misma a través de sus variaciones externas y accidentales. La restance, que a la vez es resistencia, no se deja aprehender, dominar, tematizar, reapropiar por ningún saber ni por ninguna ciencia, por ninguna ontología ni por ninguna economía. Ni tampoco deja constancia de ninguna totalidad originaria perdida, tan sólo de la ausencia de un origen único, idéntico. «Al comienzo hay la ruina», el resto, la huella que es siempre huella de otra huella de otra huella, etc. O, por decirlo de otra forma, lo que la restancia pone de manifiesto es que lo originario es la repetición, la différance como diferición (o retraso) y como diferencia (lo que no es lo mismo). En francés, no lo olvidemos, el espectro es un revenant, un (re)aparecido que comienza por reiterarse, por repetirse, por retornar. Y por hanter, por asediar. El espectro no está ni vivo ni muerto o, mejor dicho, está vivo y muerto a la vez; su forma de existir (sin existir) no se deja, pues, asimilar con la existencia, como tampoco su forma de estar en un lugar sin ocuparlo se deja reducir a una simple dicotomía de presencia/ausencia; finalmente, su forma de ver sin ser visto, de acechar, entraña inevitablemente la posibilidad de que el espectro sea siempre otro radicalmente distinto, lo cual —además de resultar, si cabe, todavía más alarmante - contamina definitivamente la ya de por sí maltrecha identidad del espectro. Por su parte, la absoluta anacronía del espectro respecto de sí mismo, el cual siempre está ya ahí y a la vez está siempre por venir, es sin duda alguna la mejor traducción del desajuste del tiempo, del presente, del impropio tener lugar del acontecimiento. Finalmente, ¿quién mejor que el espectro, que aquello que nos resulta sin duda lo más extraño, lo más inquietante, lo más unheimlich; qué mejor que su intempestividad, que su venida de repente, que su visita imprevisible e inesperada para «encarnar» al arribante absoluto, a esa singularidad irreductible de lo radicalmente otro por venir y someter a una prueba decisiva la incondicionalidad de la justicia, del respeto a la alteridad irreductible del otro, la incondicionalidad de la apertura a aquello que está por venir, de la hospitalidad ${ }^{14}$ para con ello?

${ }^{13}$ Cfr. respectivamente, por ejemplo, Points de suspension. Entretiens, París, Galilée, 1992, p. 405; op. cit., pp. 332-333; Mémoires d'aveugle. L'autoportrait et autres ruines, París, Louvre. Réunion des Musées Nationaux, 1990, p. 72.

${ }_{14}$ «La hospitalidad incondicional, la hospitalidad a la vez pura e im-posible, ¿habrá que decir que responde a una lógica de la invitación (cuando la ipseidad del en-casa acoge al otro en su propio horizonte, cuando plantea sus condiciones, pretendiendo saber a quién va a recibir, esperar e invitar, y cómo, hasta qué punto, a quién le es posible invitar, etc.) o bien a una lógica de la visitación (el anfitrión, entonces, dice que sí a la venida o al acontecimiento inesperado e imprevisible del que viene, en cualquier momento, con antelación o con retraso, en absoluta anacronía, sin ser 
[...] aprender a vivir con los fantasmas, en la charla, la compañía o el aprendizaje, en el comercio sin comercio con los fantasmas y de los fantasmas. A vivir de otra manera. Y mejor. No mejor: más justamente. Pero con ellos» ${ }^{15}$.

Estas palabras de Derrida referidas al espectro, a la relación que deberíamos mantener con lo otro espectral, son probablemente la máxima expresión de esa exigencia innegociable de su pensamiento de hacer lo imposible.

Más vale la apertura del porvenir: éste es el axioma de la deconstrucción, aquello a partir de lo cual siempre se ha puesto en movimiento, y lo que la liga, como el porvenir mismo, con la alteridad, con la dignidad sin precio de la alteridad, es decir, con la justicia ${ }^{16}$.

Para que haya acontecimiento, no basta con que algo suceda. Si conozco lo que va a suceder, lo que puede suceder, si lo preveo o lo anticipo, no se trata de un acontecimiento. Lo posible, esto es, lo previsible, lo anticipable, lo calculable no acontece ${ }^{17}$. La experiencia de lo imposible, de lo posibleimposible, como experiencia radical del quizás (condición de la promesa - esto es, de lo mejor o de lo peor; de la chance, de la suerte, o de la catástrofe- y también oportunidad para la invención y para el cambio), es la que, afirma Derrida, «involucra quizás el único pensamiento posible del acontecimiento» ${ }^{18}$. Lo imposible es el único acontecimiento posible:

Cuando lo imposible se hace posible, el acontecimiento tiene lugar (posibilidad de lo imposible). Ésta es precisamente, irrefutablemente, la forma paradójica del acontecimiento: si un acontecimiento es solamente posible, en el sentido clásico de esa palabra, si se inscribe en unas condiciones de posibilidad, si no hace más que explicitar, desvelar, revelar, realizar lo que ya era posible, entonces ya no es un acon-

invitado, sin hacerse anunciar, sin horizonte de espera: como un mesías tan poco identificable y tan poco anticipable que el nombre mismo de mesías, la figura del mesías y, sobre todo, del mesianismo, revelarían todavía cierta prisa por hacer prevalecer la invitación frente a la visitación)?

¿Cómo conformarse al sentido de lo que se denomina un acontecimiento, a saber, la venida inanticipable de lo que viene y de quien viene, al no ser entonces el sentido del acontecimiento sino el sentido del otro, el sentido de la alteridad absoluta? La invitación conserva el control y recibe en los límites de lo posible; no es, por consiguiente, pura hospitalidad; economiza la hospitalidad, pertenece todavía al orden de lo jurídico y de lo político; la visitación, por su parte, exige, por el contrario, una hospitalidad pura e incondicional que acoge lo que acontece como im-posible. La única hospitalidad posible, como pura hospitalidad, debería, pues, hacer lo imposible», en Papier Machine, ed. cit., nota 1, pp. 296-297.

15 Spectres de Marx, ed. cit., p. 15. Cfr., al respecto, mi artículo «El espectro, ça nous regarde», en C. Peretti (ed.), Espectrografias (Desde Marx y Derrida), Madrid, Trotta, 2003, pp. $27 \mathrm{ss}$.

16 «La déconstruction de l'actualité», ed. cit., p. 70.

17 Cfr., por ejemplo, op. cit., p. 66.

18 Politiques de l'anitié, ed. cit., p. 46. Y Derrida añade dos líneas más abajo: «No hay categoría más justa para el porvenir que la del quizás». 
tecimiento. Para que un acontecimiento tenga lugar, para que sea posible, es preciso que sea, como acontecimiento, como invención, la venida de lo imposible. Se trata de una pobre evidencia, una evidencia que no es nada menos que evidente. Ella es la que nunca habrá dejado de guiarme, entre lo posible y lo imposible. Ella es la que me habrá empujado tan a menudo a hablar de condición de imposibilidad ${ }^{19}$.

El acontecimiento absoluto es siempre una singularidad absolutamente otra, distinta, que no espero; algo inaudito, desconocido, imprevisible e irrepetible, aunque pueda ocurrirme una y otra vez (la iterabilidad, mezcla de repetición y de différance, es siempre diferente; por eso, tiene lugar cada vez como única vez); algo que irrumpe de golpe, de pronto, provocando un impacto, un trauma, una herida en el curso normal de la historia pero desajustando asimismo el orden del tiempo ${ }^{20}$, desbaratando su sucesión lineal, desquiciando el presente, tornándolo out of joint, intrínsecamente impropio respecto de sí mismo. Por eso, afirma Derrida, el acontecimiento nunca fue, ni es, ni será presente; su acontecer, su tener-lugar, su «aquí-ahora» singular no significa ni implica nunca presencia alguna. De ahí, pues, que el acontecimiento absoluto esté siempre por venir. Ahora bien, una vez más conviene recordar que no se trata de convertir esta apertura incondicional e ilimitada al acontecimiento por venir en un ideal, en una utopía o en una mera espera tranquilizadora. Lo por venir, precisa Derrida, es radicalmente distinto del futuro, el cual, al estar ya prefigurado en un horizonte de espera, es algo anticipable y calculable, es decir, posible. Sin embargo, lo por venir resulta en general intolerable: no sólo porque es algo que no podemos conocer, calcular ni identificar, algo que no nos podemos representar ni imaginar, sino también porque esa reserva de inseguridad y de incertidumbre que alberga necesariamente cualquier acontecimiento por venir hace que sólo seamos capaces de concebirlo como algo inquietante cuando no terrorífico, monstruoso; como el peligro absoluto:

el porvenir es necesariamente monstruoso: la figura del porvenir, es decir, de lo que no puede, sino sorprendernos, aquello para lo cual no estamos preparados [...], se anuncia bajo las especies del monstruo. Un porvenir que no fuera monstruoso no sería un porvenir, sería ya un futuro previsible, calculable y programable. [...] Toda la historia ha mostrado que cada vez que un acontecimiento se ha producido [...] ha tomado la forma de lo inaceptable, incluso de lo intolerable, de lo incomprensible, . es decir, de una cierta monstruosidad ${ }^{21}$.

${ }^{19}$ Papier Machine, ed. cit., p. 307.

${ }^{20}$ Cfr., por ejemplo, Spectres de Marx, ed. cit., pp. 41 ss. o «Auto-immunités, suicides réels et symboliques. Un dialogue avec Jacques Derrida», en J. Derrida \& J. Habermas: Le «concept» $d u$ Il septembre. Dialogues à New York (octobre-décembre 2001) avec Giovanna Borradori, París, Galilée, 2004, p. 148. p. 14.

${ }^{21}$ Points de suspension, ed. cit., pp. 400-401. Cfr. asimismo De la Grammatologie, ed. cit., 
Por otra parte, en relación con la justicia y con la apertura o afirmación incondicional de lo que está por venir, Derrida habla, en ciertas ocasiones, de «mesianicidad», de «mesianismo sin mesianismo» o de «mesianismo de antes del mesianismo»:

lo mesiánico, o la mesianicidad sin mesianismo. Sería la apertura al porvenir o a la venida del otro como advenimiento de la justicia, pero sin horizonte de espera y sin prefiguración profética ${ }^{22}$.

Cuando utiliza estas expresiones, Derrida lo hace de un modo provisional y didáctico ${ }^{23}$ con el fin de marcar la diferencia entre la fe y la religión al referirse a una dimensión universal de la experiencia radicalmente distinta de cualquier tradición mesiánica, esto es, de cualquier mesianismo concreto y determinado, de cualquier doctrina o dogma religioso, de cualquiera de los grandes mesianismos del Libro, puesto que esa «mesianicidad sin mesianismo» de la que habla Derrida excluye por lo menos dos de las condiciones fundamentales de cualquier mesianismo religioso, a saber: la memoria de una revelación histórica determinada y la figura también relativamente concreta de un mesías. Lo mesiánico, en Derrida, no sólo no está limitado a un lugar o a un pueblo privilegiado, sino que tampoco puede entenderse como una verdad, como una auténtica posibilidad trascendental $u$ ontológica.

La mesianicidad sin mesianismo, como estructura universal de la experiencia, será, entonces, la apertura al porvenir de un acontecimiento sin mesías, de una modalidad de venida que carece de forma determinada; una especie de «desierto en el desierto» en el que se espera sin esperar, sin esperar nada concreto, «espera árida y privada de horizonte», espera sin espera inseparable de la afirmación de la justicia y de la alteridad irreductible del otro; inseparable asimismo de la apertura al acontecimiento por venir, al arribante absoluto, al otro espectral; inseparable también, finalmente, de la (profesión de) fe, del crédito o de la creencia (anterior a cualquier religión pero igualmente más allá de cualquier posibilidad constatativa) en la palabra dada, en la promesa, como estructura de todo contrato social, de toda vida en sociedad $y$, por consiguiente, de cualquier intervención política ${ }^{24} \mathrm{o}$ de cualquier decisión ética.

${ }_{22}$ «Foi et savoir. Les deux sources de la 'religion' aux limites de la simple raison», en J. Derrida \& G. Vattimo (dirs.), La religion. París, Seuil, 1996, p. 27. Asimismo, por ejemplo: «la mesianicidad es, en todo aquí ahora, la referencia a la venida del acontecimiento más concreto y más real, es decir, a la apertura más irreductiblemente heterogénea», en Marx \& Sons, París, PUF/Galilée, 2002, p. 69. Cfr., igualmente, Spectres de Marx, ed. cit., pp. 266-267.

${ }_{23}^{23}$ Cfr. Marx \& Sons, ed. cit., pp. 79-80.

24 «Si hay un espíritu del marxismo al que yo no estaría dispuesto a renunciar, éste no es solamente la idea crítica o la postura cuestionadora [...] Es más bien cierta afirmación emancipatoria y mesiánica, cierta experiencia de la promesa que se puede intentar liberar de toda dogmática e, incluso, de toda determinación metafísico-religiosa, de todo mesianismo" (Spectres de Marx, ed. cit., pp. 147-148). 
Hasta aquí, he tratado de exponer las que son, a mi entender, las principales aportaciones que Derrida nos ha dejado en aquellos textos suyos redactados a partir de los años noventa y más explícitamente preocupados por cuestiones pertenecientes a lo que tradicionalmente denominamos el terreno de la ética y de la política. Esto no significa - como con frecuencia se ha pretendido decir- que, en sus textos anteriores, Derrida sea ajeno a dichas cuestiones. Su pensamiento jamás ha sido apolítico. Así lo confirman, por una parte, los bien conocidos y muy numerosos compromisos políticos personales que ha suscrito Derrida desde que empezó a escribir hasta su muerte. Por otra parte, el lector que sepa y quiera leer puede encontrar ya, en los primeros escritos derridianos sólo en apariencia más teóricos, más especulativos, más estrictamente filosóficos todo tipo de vinculaciones y de implicaciones ético-políticas, así como una preocupación constante por repensar políticamente toda una serie de ámbitos tradicional y supuestamente inocentes e inofensivos del discurso filosófico hegemónico pero, en realidad, dominados por unos campos de fuerza, unos códigos, unas jerarquías y unas violencias fundadoras:

... lo que yo propongo aquí - afirma Derrida, refiriéndose a su pensamiento de las últimas décadas - no dibuja ningún ethical turn, como ha podido decirse, lo mismo que tampoco lo hacen las anteriores alusiones a la responsabilidad, a la hospitalidad, al don, al perdón, al testimonio, etc. Intento únicamente llevar adelante con cierta coherencia un pensamiento comprometido desde hace tiempo con las mismas aporías. La cuestión de la ética, del derecho o de la política no surgió ahí de improviso, como a la vuelta de la esquina. La manera en que es tratada no siempre es, por lo demás, tranquilizadora para una «moral» - y quizás porque le pide demasiado- 25 .

En efecto, desde que empezó a escribir a principios de los años sesenta, Derrida no ha dejado de denunciar y de «solicitar» ${ }^{26}$ lo que él denomina con frecuencia la «hegemonía de lo homogéneo», esto es, los totalitarismos, los oscurantismos, los dogmatismos y los fanatismos, así como muchas adherencias más o menos residuales que impregnan y reproducen a su vez muchos discursos y modos de comportamiento aparentemente incriminatorios de aquéllos; cualquier forma de violencia, de jerarquización, de dominación, de soberanía o de apropiación, pero también aquella reivindicación de pertenencia que defiende a ultranza la identidad, la mismidad, la homogeneidad y que - rechazando y resguardándose de la diversidad, de la plurali-

${ }^{25}$ Papier Machine, ed. cit., p. 306.

${ }^{26}$ «Solicitar significa, en latín antiguo, conmover como un todo, hacer temblar en su totalidad», Marges - de la philosophie, París, Minuit, 1972, p. 22. Asimismo: «Esta operación se denomina (en latín) inquietar o solicitar. Dicho de otro modo, conmover mediante una conmoción que atañe al todo (de sollus, en latín arcaico: el todo, y de citare: empujar)», en L'écriture et la différence. París, Seuil, 1967, p. 13. 
dad, de la diferencia inasimilable: lo otro, lo distinto, lo extraño, lo ajeno, lo im-propio, lo unheimlich siempre molesto, inquietante, amenazador, peligroso- ejerce toda suerte de represión, de exclusión y de marginación.

Ya por entonces, la concepción derridiana de la escritura, de lo que Derrida denomina también la (archi) escritura, entendida como grama (posibilidad de toda inscripción en general) o différance ${ }^{27}$, constituye una vía de liberación tanto frente a la soberanía del $\log o{ }^{28}$, frente a la pretensión de universalidad de la razón como frente al horizonte de comunicación entendido como comunicación de conciencias o de presencias, como vehículo lingüístico del querer-decir, de una unidad de sentido. A ello contribuyen igualmente la nociones derridianas de texto (entendido como un proceso significante general, como una red nodal de significaciones que conforma, por consiguiente, una realidad más amplia y compleja ${ }^{29}$ que la del tradicional texto escrito), de injerto textual ${ }^{30}$ (tejido interminable de textos que se entrecruzan unos con otros generando constantemente nuevos textos dentro

27 «Se trata de producir un nuevo concepto de escritura. Se lo puede llamar grama o différance», Positions, París, Minuit, 1972, p. 37.

En lo que respecta, más concretamente, a la différance, «motivo» insoslayable dentro del pensamiento derridiano, cfr. muy especialmente el artículo del mismo nombre publicado en Marges de la philosophie, ed. cit., pp. 3 ss.

28 Desde sus primeros escritos, Derrida destaca como estructura predominante de la tradición metafísica (que, por lo demás, en modo alguno puede considerarse como algo homogéneo) la ilusión de la presencia total, la cual se traduce en la sistemática complicidad del logocentrismo (el cual se rige por una lógica binaria jerarquizada que otorga el privilegio a aquello que se considera más cercano al logos) con el fonocentrismo (primacía de la voz como relación originaria de la conciencia y del significado).

${ }^{29}$ «Lo que todavía llamo 'texto' por razones parcialmente estratégicas [...] ya no sería [...] un corpus finito de escritura, un contenido enmarcado en un libro o en sus márgenes, sino una red diferencial, un tejido de huellas que remiten indefinidamente a algo otro, que están referidas a otras huellas diferenciales. A partir de ese momento, el texto desborda, pero sin ahogarlos en una homogeneidad indiferenciada, sino complicándolos por el contrario, dividiendo y multiplicando el trazo, todos los límites que hasta aquí se le asignaban, todo lo que se quería distinguir para oponerlo a la escritura (el habla, la vida, el mundo, lo real, la historia, ¡qué sé yo aún!, todos los campos de referencia física, psíquica - consciente o inconsciente-, política, económica, etc.)», en Parages, París, Galilée, 1986, pp. 127-128.

30 «Escribir quiere decir injertar. Es la misma palabra. El decir de la cosa es devuelto a su ser-injertado. El injerto no sobreviene a lo propio de la cosa. No hay cosa como tampoco hay texto original.

De este modo, todas las extracciones textuales [...] no dan lugar -como se hubiera podido suponer-a «citas», a «collages», ni siquiera a «ilustraciones». Aquéllas no se aplican a la superficie o en los intersticios de un texto que ya existiría sin ellas. Y ellas mismas no se leen sino en la operación de su reinscripción, en el injerto. Violencia insistente y discreta de una incisión inaparente en el espesor del texto, inseminación calculada de lo alógeno en proliferación, gracias a la cual ambos textos se transforman, se deforman uno al otro, se contaminan en su contenido, tienden a veces a rechazarse, pasan elípticamente del uno al otro y, así, se regeneran en la repetición, en el borde de un punto por encima. Cada texto injertado continúa irradiando hacia el lugar de su extracción y también lo transforma afectando al nuevo terreno. Es definido (pensado) por dicha operación a la vez que él define (piensa) la regla y el efecto de la operación», en La dissémination, París, Seuil, 1972, p. 395. 
de un proceso de significación plural) y de diseminación ${ }^{31}$ (proliferación significativa y «seminal» irreductible a la polisemia hermenéutica), las cuales resquebrajan los valores y las garantías del libro entendido como «buena escritura», como una totalidad cerrada y natural sometida al orden lineal y avalada por la asignación de propiedad de la misma a la identidad ilusoria de un nombre propio, de una firma autentificadora, de un autor como padre originario, propietario e instancia última de su sentido. Los conceptos de origen (original frente a copia; texto original frente a traducción), de propiedad pero también de contexto (cuyo límite se torna de este modo insaturable) quedan así desbaratados y la única ley de significación del texto resulta ser la ley del exceso indecidible.

Por lo demás, para Derrida, resulta «preciso con un solo gesto, aunque desdoblado, leer y escribir» ${ }^{32}$. Este gesto único aunque doble, además de ser un recurso estratégico imprescindible, constituye un antecedente de esa experiencia aporética en la que consiste la deconstrucción derridiana. Por una parte, dicho gesto nos remite asimismo, de nuevo, a la cuestión de la herencia, la cual - recordémoslo- para Derrida sólo se puede asumir volviéndola a inventar, esto es, repitiéndola y reescribiéndola al tiempo que se la transforma, que se le es infiel por fidelidad. En este sentido, la lectura derridiana de la tradición filosófica no será nunca un comentario en el sentido tradicional, el cual, con la ilusión de lograr desvelar por completo su significado, se enfrenta a un pensamiento como un sistema acabado y cerrado, a un texto que, avalado por un nombre propio, resulta aparentemente intacto y sin fisuras.

La tarea que, como heredero de dicha tradición, emprende Derrida, lo que solemos denominar deconstrucción, constituye una palanca de intervención activa, minuciosa y rigurosa que «solicita» todo aquello que ya está, desde siempre, en deconstrucción: todo arte del sistema, toda presunta totalidad pero también cualquier texto, cualquier experiencia, cualquier «realidad» en donde se repite «cierta dislocación» precisamente allí donde parece haber un mayor fundamento, seguridad o solidez: los valores, códigos y jerarquías que sustentan la gran arquitectónica de la tradición de Occidente:

${ }^{31}$ Cfr., por ejemplo, op. cit., pp. 337-338.

32 «Si hay una unidad de la lectura y de la escritura, tal como se piensa fácilmente hoy en día, si la lectura es la escritura, dicha unidad no designa ni la confusión indiferenciada ni la tranquila identidad: el es que une la lectura con la escritura ha de descoserlas en parte.

Sería, pues, preciso, con un solo gesto, pero desdoblado, leer y escribir. Y quien se creyese, por eso mismo, autorizado a añadir, es decir, a añadir cualquier cosa, no habría entendido nada del juego. No añadiría nada, la costura no se mantendría. Recíprocamente, ni siquiera leería aquel a quien la "prudencia metodológica", las "normas de la objetividad" y los "parapetos del saber" le coartasen para poner algo de su propia cosecha. Idéntica simpleza, idéntica esterilidad de lo "no serio" y de lo "serio". El suplemento de lectura o de escritura debe ser rigurosamente prescrito pero por la necesidad de un juego, signo al que hay que conceder el sistema de todos sus poderes», op. cit., p. 72 . 
En unos contextos siempre muy determinados, [la deconstrucción] es uno de los nombres posibles para designar, en resumidas cuentas metonímicamente, lo que llega o no llega a llegar, a ocurrir, es decir, una cierta dislocación que de hecho se repite con regularidad [...] en lo que se denomina clásicamente los textos de la filosofía clásica, por supuesto y por ejemplo, pero asimismo en cualquier texto, en el sentido general que trato de justificar para dicha palabra, es decir, en la experiencia sin más, en la «realidad» social, histórica, económica, técnica, militar, etc. [...] ello ocurre, no espera a que fínalice el análisis filosófico-teórico [...]: éste es necesario pero infinito y la lectura que esas fisuras hacen posible no sobrevuela jamás el acontecimiento; tan sólo interviene en él, está inscrita en él ${ }^{33}$.

Reescribiendo sobre los textos, no acerca de ellos, sino en ellos, dentro de ellos, en su interior, Derrida relee esta tradición que hereda: analiza los estratos y sedimentos que configuran la discursividad dentro de la cual pensamos; interroga sus presupuestos, sus categorías, sus límites y sus márgenes con el fin de abrir nuevas perspectivas de pensamiento y otros posibles sentidos que los ya refrendados por la tradición a lo largo de las distintas lecturas y transmisiones; asimismo describe la estructura interna de los textos, su entramado, así como la lógica que los rige, atendiendo a todo tipo de efectos no siempre controlados que allí obran y en los que el pensamiento se excede a sí mismo: los hilos que los tejen pero también sus líneas de fractura, sus resquicios y sus fisuras, sus paradojas, sus marcas textuales así como otros elementos marginales, tradicionalmente ignorados, que pueden orientar secretamente la problemática de un texto y lo que en él está en juego; desplazando ciertos motivos, reiterándolos y alterándolos a la vez, con el fin de que, al sustraerlos a los sistemas rígidos de referencia que les imponen un determinado lugar y limitan su fecundidad, aquéllos puedan trabajar otras cuestiones, otros textos, otros ámbitos.

Todo esto requiere no sólo que intervengan todo tipo de estrategias de descentramiento, de desplazamiento, de desestabilización que, lejos de constituir un método, esto es, «un conjunto disponible de procedimientos regulados» y de reglas prácticas que se pueden enseñar y aplicar siempre, han de replantearse en cada ocasión y de inventarse de nuevo cada vez de acuerdo con la singularidad e irrepetibilidad de aquello que, en cada momento, está en deconstrucción ${ }^{34}$; requiere asimismo escribir siempre a dos manos, mediante ese solo gesto siempre - como ya apuntamos - desdoblado.

Derrida nunca ha dejado de moverse dentro de las estructuras de la metafísica, pero, mientras, con una mano, respeta su juego, con la otra mano, pone de manifiesto sus grietas, desplaza sus conceptos, desbarata su lógica

${ }^{33}$ Points de suspension, ed. cit., pp. 367-368.

34 Por eso mismo, Derrida prefiere también que no se hable de «la» deconstrucción, en singular, sino de «deconstrucciones», en plural, pues cada vez es una y sólo una, una deconstrucción singular, una lectura irrepetible, la que interviene y se inscribe en lo que está en deconstrucción. Cfr., por ejemplo, op. cit., p. 367. 
oposicional binaria y sus correspondientes jerarquías, logrando de este modo hacer temblar en su totalidad un edificio aparentemente sólido. La larga lista de términos que Derrida denomina «indecidibles» («unidades de simulacro, 'falsas' propiedades verbales, nominales o semánticas, que ya no se dejan encerrar en la oposición filosófica (binaria) y que, no obstante, la habitan, resisten a ella, la desorganizan pero sin constituir jamás un tercer término, sin dar nunca lugar a una solución bajo la forma de la dialéctica especulativa [...] Ni/ni, es a la vez o bien o bien» ${ }^{35}$ ): es un buen ejemplo de la estrategia derridiana del doble gesto, así como también lo son las distintas «lógicas» plurales y paradójicas (me refiero, por ejemplo, a la lógica del suplemento ${ }^{36}$, a la de la restance, «restancia» - huella, ceniza, resto, ruina- o a la de la espectralidad) que Derrida va tejiendo al hilo de su escritura y que van minando y contaminando a la vez - repito- la ilusión de una presencia plena, de una totalidad originaria, de un origen único.

Finalmente, a ese gesto siempre desdoblado, se une la necesidad, señala Derrida, de «hablar varias lenguas y producir varios textos a la vez» 0 , como afirmará a menudo más adelante, la necesidad de «más de una lengua» ${ }^{37}$. Con esto, Derrida está apuntando a la traducción como una tarea imprescindible a la vez que imposible ${ }^{38}$, pero también a ese otro movimiento de traslación que, en la lengua, conduce hacia el otro, hacia su lengua, hacia la lengua del otro ${ }^{39}$. La oportunidad de la lengua, esto es, de la promesa pero asimismo del don y de la hospitalidad sólo pueden acontecer gracias al otro, a su lengua y a su venida. Derrida no está hablando aquí de propiedad ni de pertenencia de la lengua, sino, por el contrario, de su «ex-apropiación» más radical. La lengua es siempre lengua del otro aunque además, dentro de una misma lengua, siempre hay «más de una lengua». Con ello, lo que está en deconstrucción es, una vez más, lo que Derrida denomina «la hegemonía de lo homogéneo» la cual designa aquí, por una parte, la unidad de cualquier sistema lingüístico, su identidad, su integridad así como su presunta transparencia, su inteligibilidad y su legibilidad sin restos; $y$, por otra parte, esa otra violencia homogeneizadora que pretende implantar el predominio de una lengua sobre otra. Estamos hablando de imperialismo, de soberanía, de colonización y éstos, evidentemente, no se limitan sólo a una cuestión lingüística.

Resulta difícil poner el punto final a un artículo en el que se habla del legado que nos deja un pensamiento como el de Derrida, incondicionalmente abierto a aquello que está por venir. La herencia de Derrida, sin duda

\footnotetext{
${ }^{35}$ Positions, ed. cit., p. 58.

${ }^{36}$ Cfr., por ejemplo, De la grammatologie, ed. cit., p. 208.

37 Respectivamente Marges - de la philosophie, ed. cit., p. 163 y, por ejemplo, Mémoires pour Paul de Man, París, Galilée, 1988, p. 38.

${ }^{38}$ Cfr., al respecto, por ejemplo, Parages, ed. cit., passim; $\mathrm{Cl}$. Lévesque \& Ch. McDonald (eds.), L'oreille de l'autre, VLB, Montreal, 1982, pp. 132 ss.; «Des tours de Babel», en Psyché, ed. cit., pp. 203-235.

${ }^{39}$ Cfr. Le monolinguisme de l'autre, París, Galilée, 1996, passim.
} 
alguna, también lo está aunque ya sean muchos los ámbitos que, a lo largo de todos estos años, se hayan ido haciendo cargo de la deconstrucción: me refiero no sólo a la filosofía y a la crítica literaria, sino asimismo a la estética, el derecho, la arquitectura, el (vídeo)cine así como numerosos estudios de colectivos minoritarios cuando no marginados (que van desde el feminismo hasta los estudios sobre postcolonialismo), aunque quizá tampoco habría que dejar de citar el más novedoso y curioso de todos estos campos: el de la cocina cuyo máximo representante es el catalán Ferrán Adriá. Pero también es cierto que «hay deconstrucción y deconstrucción [...] No lo olvidemos nunca si queremos no mezclar todas las 'deconstrucciones' de este momento. $\mathrm{Y}$ del mundo» ${ }^{40}$, apunta Derrida. No lo olvidemos a la vista del uso indiscrimado, del descomunal abuso que, hoy en día, se está haciendo de este término.

Por el momento, a mí ya no me queda más que interrumpir este rápido y necesariamente inconcluso esbozo de lo que el pensamiento derridiano nos deja en herencia, pero no lo haré sin antes recordar unas palabras publicadas en la última entrevista que Derrida le concedió al periódico Le Monde poco tiempo antes de su muerte:

A mi edad, estoy dispuesto a las hipótesis más contradictorias al respecto: tengo simultáneamente, le ruego que me crea, el doble sentimiento de que, por un lado, por decirlo con una sonrisa y de forma inmodesta, todavía no se ha comenzado a leerme; de que si bien, ciertamente, hay muchos lectores muy buenos (algunas decenas en el mundo quizás), en el fondo, es más tarde cuando todo esto tiene oportunidad de aparecer; pero asimismo, por otro lado, de que, quince días o un mes después de mi muerte, no quedará nada. Salvo lo que se conserva mediante el depósito legal en biblioteca. Se lo juro, creo sincera y simultáneamente en ambas hipótesis ${ }^{41}$.

\footnotetext{
${ }^{40}$ Le toucher, Jean-Luc Nancy, París, Galilée, 2000, p. 74.

41 «Je suis en guerre contre moi-même», en Le Monde, 19 de agosto de 2004, y publicado, por segunda vez, en Le Monde del martes 12 de octubre de 2004 en un «Cahier» (núm. 18572) dedicado a Derrida tras su muerte.
} 